\title{
Granular cell tumor involving the axillary nerve: an unusual occurrence
}

\section{Case report}

\author{
Stefan A. Mindea, M.D., Keith J. Kaplan, M.D., Michael A. Howard, M.D., \\ and Shaun T. O'Leary, M.D., Ph.D. \\ Northwestern Memorial Hospital and Evanston Northwestern Healthcare, Evanston, Illinois
}

\begin{abstract}
$\checkmark$ Granular cell tumors (GCTs) are benign lesions that, paradoxically, despite originating from the Schwann cell, are most commonly seen in nonneuronal tissue including the skin, subcutaneous tissue, and tongue. Their presence in the brachial plexus is quite rare, but their involvement of peripheral nerves is exceptional. The authors report on a case of GCT involving the axillary nerve in a 54-year-old woman who underwent complete resection of the lesion. To the author's knowledge, this case marks the first report of a GCT involving the axillary nerve. Aspects pertaining to the radiographic and histopathological features as well as the surgical management of this lesion are discussed.
\end{abstract}

KEY WORDS • axillary nerve • granular cell • peripheral nerve tumor

$\mathrm{G}$ RANULAR cell tumors are relatively common extraneural lesions, the majority of which are regarded as benign neoplasms. They occur most frequently in the skin, subcutaneous tissue, tongue, and other nonneuronal tissue, although the tumor appears to be of Schwann cell origin on the basis of morphological and immunohistochemical assessments. ${ }^{5,17}$ Their presence in the brachial plexus and peripheral nerves is an extremely rare occurrence, and to our knowledge, this case marks the first reported instance of a GCT involving the axillary nerve.

\section{Case Report}

History and Examination. In January 2006, this 54-yearold right-handed woman with a history of recurrent rightsided breast cancer, who had previously been treated with lumpectomy and axillary node dissection 9 years earlier and bilateral mastectomies with TRAM reconstruction 1 month earlier, presented with a 2-month history of severe right upper-extremity pain. She described the pain as searing and burning in quality and localized to the right lateral upper arm. The pain was more severe at night and frequently awakened her from sleep. Her neurological examination revealed diminished pinprick sensation over her deltoid, but no paresis was present. She was able to abduct her arm and shoulder with normal strength, and no muscle atrophy was noted. A magnetic resonance image of the brachial plexus revealed a $2.6 \times 1.8 \times 3-\mathrm{cm}$ soft tissue mass located pos-

Abbreviations used in this paper: GCT = granular cell tumor; TRAM $=$ transverse rectus abdominus flaps. terior to the proximal humeral diaphysis, between the long head of the triceps muscle and the deltoid muscle, and adjacent to the posterior humeral circumflex vessels and axillary nerve (Fig. 1). The soft tissue mass demonstrated low signal intensity on T1-weighted images and high signal intensity on T2-weighted images and exhibited robust homogeneous postcontrast enhancement with no evidence of the involvement of adjacent structures. Given the presence of this mass in light of the patient's history of breast cancer, resection was planned for definitive tissue diagnosis and removal of the mass.

Operation. In a posterior right arm approach, a skin incision was made lateral to the deltoid and was extended upward, just inferior to the spine of the scapula. The fascia was then opened, the deltoid was reflected anteriorly, and the teres (major and minor) and triceps muscles were all identified. A large, white sclerotic mass measuring approximately $3 \times 3 \mathrm{~cm}$ was noted encircling the axillary nerve. This mass appeared well circumscribed and appeared to displace the anterior branch of the axillary nerve medially, whereas it infiltrated the posterior branch of the nerve supplying the teres minor and lateral superficial cutaneous nerves. After identifying the proximal and distal aspects of the axillary nerve, the tumor was meticulously dissected away from the proximal anterior portion of the axillary nerve and was eventually successfully shelled from the nerve. Utilizing intraoperative electrophysiological stimulation, the proximal motor branches innervating the teres minor muscle and the deltoid muscles were both confirmed to be functional.

We then directed our attention to the posterior branch of 

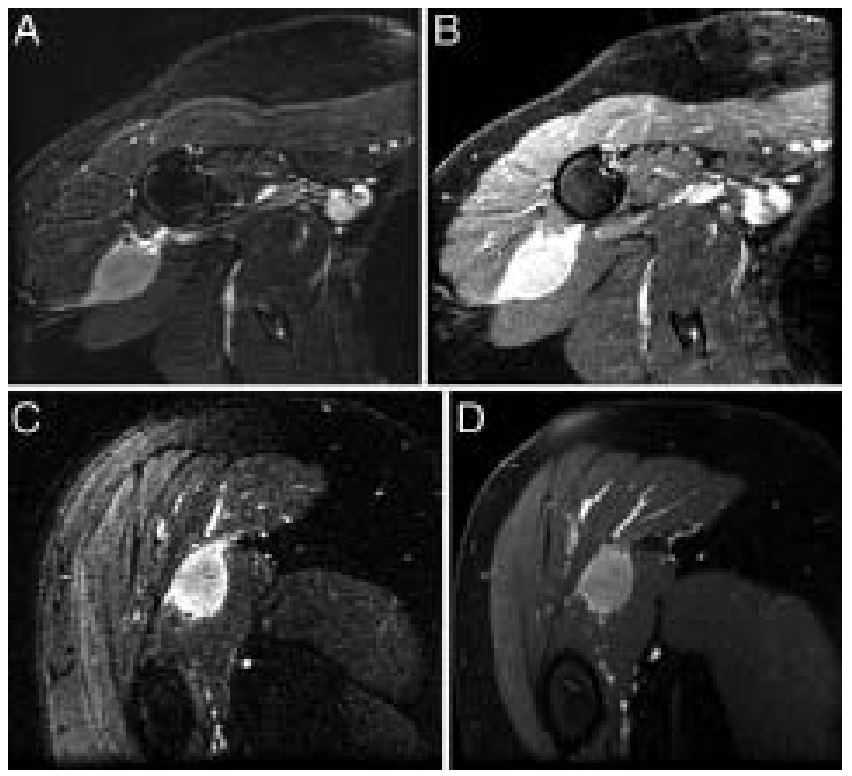

FIG. 1. Fat-saturated magnetic resonance images of the brachial plexus before (A and $\mathrm{B}$ ) and after (C and D) Gd infusion, demonstrating the enhancing soft tissue mass located posterior to the proximal humeral diaphysis and between the long head of the triceps and the deltoid muscles.

the axillary nerve, where a small motor branch to the deltoid muscle and the lateral superficial nerve appeared to be encased by tumor. Because of this extensive involvement, neurolysis of these two branches was performed, and the tumor was successfully resected. We contemplated grafting to the larger cutaneous nerve innervating the lateral portion of the arm to maximize sensation to this area but believed that a graft in this region, which would only potentially offer sensation to the lateral portion of the arm, was not worth the guaranteed risk of numbness in the foot where the donor nerve graft would be harvested. Therefore, we deferred nerve grafting, and in this scenario the wound was closed in a standard fashion.

Pathological Studies. A firm brown nodule with an irregular outer surface and no evidence of necrosis or hemorrhage was noted. Histological analysis demonstrated a cellular neoplasm composed of bland monotonous cells with abundant granular eosinophilic cytoplasm and centrally located pyknotic nucleoli with inconspicuous nucleoli and a lack of necrosis or mitoses (Fig. 2). The tumor cells were negative for carcinoembryogenic antigen, myelin basic protein, and calretinin but stained positive for $\mathrm{S} 100$ protein with numerous lysozymes identified in the cytoplasm; the diagnosis was consistent with a GCT of the axillary nerve.

Postoperative Course. At the patient's 2-month postresection visit, she reported incomplete improvement of the paresthesias in the lateral upper portion of her arm but no subjective neurological weakness. Closer evaluation of individual muscle groups did in fact reveal trace weakness in the deltoid. The patient also demonstrated some limitation in the range of motion in her shoulder, which we ascribed to the mastectomies and the TRAM performed 3 months earlier. At 14 months after the tumor resection, she described herself as having no functional limitations whatsoever and resolution of the arm paresthesia.

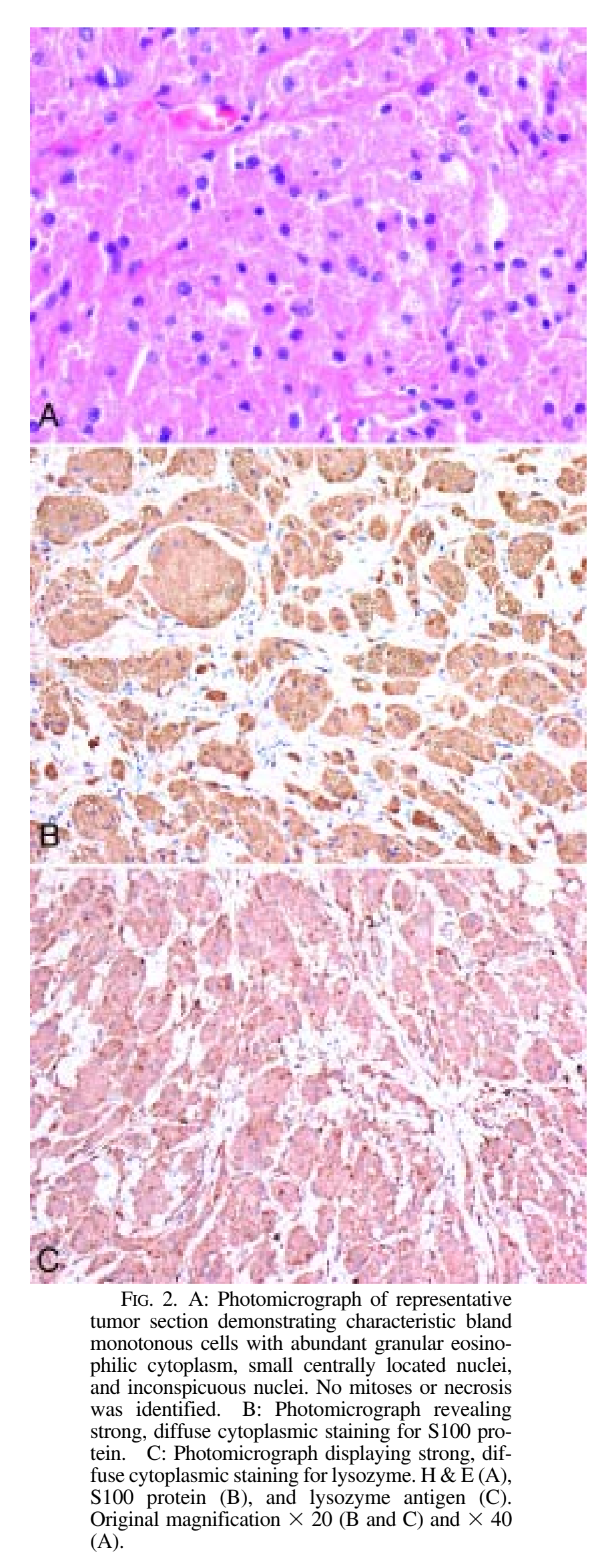




\section{Discussion}

Granular cell tumors are exceedingly rare peripheral nerve tumors. Although these tumors have been demonstrated to have a neural origin, they rarely arise in peripheral nerve trunks. In Kim and colleagues' 30-year review detailing the treatment of 543 peripheral nerve tumors, only two GCTs were reported, both of which involved the brachial plexus and not the peripheral nerve trunks. ${ }^{8,9} \mathrm{~A}$ review of the literature from the last 10 years has revealed reports of only three GCTs involving the ulnar nerve and one involving the sural nerve., ${ }^{3,418}$ It remains to be elucidated why these lesions do not involve the peripheral nerves more frequently, which would be surmised from their neural origin.

Most GCTs occur in the skin or subcutaneous tissue of middle-aged adults with a slight female predominance, although the overall age range is wide. Virtually any anatomical site can be affected, but the trunk and tongue are the most common locations. Lesions in the breast, biliary tree, and larynx have been reported..$^{15} \mathrm{Up}$ to $10 \%$ of patients with GCTs have multiple lesions, which are more common in African-Americans. ${ }^{6}$ In most cases the tumor is slow growing, rarely causes tenderness, and usually measures less than $3 \mathrm{~cm}$ in its maximum dimension. The local recurrence rate in benign lesions is less than 5\% and usually reflects incomplete excision.

Granular cell tumors seldom present a diagnostic problem histologically. Although granular cells can be encountered in schwannoma or neurofibroma, the differing basic nature of these tumors is readily apparent. Some lesions must be distinguished from rhabdomyoma, histiocytoid carcinoma (for example, from the breast), or infrequently a reactive lesion complicating previous trauma or inflammation. ${ }^{16}$ Rare variants of GCT include gingival GCT in newborn infants, ${ }^{11}$ primitive polypoid GCT, ${ }^{12}$ and malignant $\mathrm{GCT}^{6}{ }^{6,7,10}$

Most benign GCTs present as solitary masses, most frequently involving the upper extremities and exhibiting symptoms caused by neural compression rather than primary involvement of the nerve. ${ }^{3,4,18}$ Treatment for these lesions entails wide local excision with tumor-free surgical margins, which usually prevents recurrence in cases of benign and extraneural tumors. Because GCTs can occasionally infiltrate the nerve, however, complete extirpation may not be feasible. ${ }^{2}$ Almost invariably, there is some degree of microscopic infiltration of the nerve fascicles by the tumor cells even if the tumor can be dissected and shelled from the nerve. Therefore, a wide surgical exposure is utilized so that the proximal and distal anatomy relative to the tumor are clearly visualized. Safe microsurgical removal of the mass can then be attempted by skeletonizing the mass from the involved nerve. If the involved peripheral nerve is completely infiltrated by tumor, however, a segmental resection with nerve reconstruction should be considered.

Malignant GCTs account for no more than 2 to $3 \%$ of all GCTs. ${ }^{1,10}$ They seem to occur mainly in the deep soft tissues of adults and are often associated with an underlying malignancy. Most often they directly extend or metastasize to a nerve and can secondarily involve the nerve and insinuate themselves into the epineurium, perineurium, and eventually the individual nerve fascicles themselves. Among the approximately 30 cases reported in the literature, more than $50 \%$ have had a metastasizing fatal course. Because of their rate of growth and degree of invasion, nerve preservation is not feasible, and these lesions are treated with segmental resection and nerve reconstruction. Criteria for their recognition are hard to define, given that some cases have appeared remarkably bland and monomorphic histologically. ${ }^{13,14}$ Nonetheless, any unusually large lesion with infiltrative margins, prominent nucleoli, and conspicuous mitoses should be regarded with suspicion.

\section{References}

1. Becelli R, Perugini M, Gasparini G, Cassoni A, Fabiani F: Abrikossoff's tumor. J Craniofac Surg 12:78-81, 2001

2. Condit DP, Pochron MD: Granular cell tumor of the palmar cutaneous branch of the median nerve. J Hand Surg [Am] 16: 71-75, 1991

3. Daentzer D, Schmidinger A, Boker DK: Atypical granular cell tumor of the sural nerve mimicking a Schwannoma. Acta Neurochir (Wien) 145:1019-1020, 2003

4. Dahlin LB, Lorentzen M, Besjakov J, Lundborg G: Granular cell tumor of the ulnar nerve in a young adult. Scand J Plast Reconstr Surg Hand Surg 36:46-49, 2002

5. Fisher ER, Wechsler H: Granular cell myoblastoma-a misnomer. Electron microscopic and histochemical evidence concerning its Schwann cell derivation and nature (granular cell schwannoma). Cancer 15:936-954, 1962

6. Khansur T, Balducci L, Tavassoli M: Granular cell tumor. Clinical spectrum of the benign and malignant entity. Cancer 60: 220-222, 1987

7. Khansur T, Balducci L, Tavassoli M: Identification of desmosomes in the granular cell tumor. Implications in histologic diagnosis and histogenesis. Am J Surg Pathol 9:898-904, 1985

8. Kim DH, Murovic JA, Tiel RL, Moes G, Kline DG: A series of 146 peripheral non-neural sheath nerve tumors: 30-year experience at Louisiana State University Health Sciences Center. J Neurosurg 102:256-266, 2005

9. Kim DH, Murovic JA, Tiel RL, Moes G, Kline DG: A series of 397 peripheral neural sheath tumors: 30 -year experience at Louisiana State University Health Sciences Center. J Neurosurg 102:246-255, 2005

10. Klima M, Peters J: Malignant granular cell tumor. Arch Pathol Lab Med 111:1070-1073, 1987

11. Lack EE, Worsham GF, Callihan MD, Crawford BE, Vawter GF: Gingival granula cell tumors of the newborn (congenital "epulis"): a clinical and pathologic study of 21 patients. Am J Surg Pathol 5:37-46, 1981

12. LeBoit PE, Barr RJ, Burall S, Metcalf JS, Yen TS, Wick MR: Primitive polypoid granular-cell tumor and other cutaneous granular-cell neoplasms of apparent nonneural origin. Am J Surg Pathol 15:48-58, 1991

13. Ordonez NG: Granular cell tumor: a review and update. Adv Anat Pathol 6:186-203, 1999

14. Ordonez NG, Mackay B: Granular cell tumor: a review of the pathology and histogenesis. Ultrastruct Pathol 23:207-222, 1999

15. Peterson LJ: Granular-cell tumor. Review of the literature and report of a case. Oral Surg Oral Med Oral Pathol 37:728-735, 1974

16. Sobel HJ, Churg J: Granular cells and granular cell lesions. Arch Pathol 77:132-141, 1964

17. Stefansson K, Wollmann RL: S-100 protein in granular cell tumors (granular cell myoblastomas). Cancer 49:1834-1838, 1982

18. Yasutomi T, Koike H, Nakatsuchi Y: Granular cell tumor of the ulnar nerve. J Hand Surg [Br] 24:122-124, 1999

\section{Manuscript submitted March 30, 2007}

Accepted April 24, 2007.

Address reprint requests to: Stefan A. Mindea, M.D., 676 East St. Claire, Suite 2200, Chicago, Illinois 60611. email: smindea@ gmail.com. 